\title{
Activation of Human Monocyte-derived Macrophages with Lipopolysaccharide Decreases Human Immunodeficiency Virus Replication In Vitro at the Level of Gene Expression
}

\author{
Michael S. Bernstein, Sandra E. Tong-Starksen, and Richard M. Locksley \\ Department of Medicine, University of California San Francisco, San Francisco, California 94143-0654
}

\begin{abstract}
Activation of $T$ lymphocytes infected with the human immunodeficiency virus-1 (HIV-1) results in enhancement of viral replication mediated in part by activation of cellular NFkB capable of binding directly to sequences in the viral long terminal repeat, or LTR. Together with CD4+ T cells, macrophages constitute a major target for infection by HIV-1. Unlike lymphocytes, however, stimulation of mononuclear phagocytes is not associated with cell division and proliferation. Human monocyte-derived macrophages transfected with HIV-LTR-CAT constructs demonstrated down-regulation of CAT activity after stimulation with bacterial lipopolysaccharide (LPS) that mapped to a region distinct from NFkB binding sites. In contrast, fresh monocytes and the promonocytic U937 cell line both demonstrated up-regulation of HIV-LTR-CAT expression by LPS. Differentiation of U937 by PMA to establish a nondividing phenotype resulted in down-regulation of transfected HIV-LTR-CAT activity by LPS similar to that in mature macrophages. Human monocyte-derived macrophages infected with HIV-1 in vitro demonstrated a decrease in viral p24 release after incubation in LPS that was comparable to the negative regulation that occurred in the transient transfection assays. Factors controlling HIV replication may differ in dividing and nondividing hematopoietic cells and may contribute to restricted viral expression in nondividing cells. (J. Clin. Invest. 1991 . 88:540-545.) Key words: U937 cells $\bullet$ LTR • transfection - endotoxin - NF $k B$
\end{abstract}

\section{Introduction}

Activation of $\mathrm{T}$ lymphocytes infected with HIV with a variety of stimuli, including phorbol esters, lectins, and signalling through the $T$ cell receptor, results in enhanced viral replication eventually associated with destruction of these cells in vitro and their depletion in vivo (1-4). Posttranscriptional induction of cellular nuclear factor $\kappa \mathrm{B}(\mathrm{NF} \kappa \mathrm{B})^{1}$ after activation may

A preliminary report of this work was presented at the National Meeting of the American Federation for Clinical Research in Washington, DC, on 5 May 1990, and was published in abstract form (1990. Clin. Res. 38: 279A). 1991.

Received for publication 19 July 1990 and in revised form 5 March

1. Abbreviations used in this paper: $\mathrm{CAT}$, chloramphenicol acetyltransferase; LTR, long terminal repeat; NF $\kappa$ B, nuclear factor $\kappa \mathrm{B}$; tat, HIV-1 transactivating protein; TAT, plasmid encoding SV-40 promoterHIV $_{\text {SF2 }}$ tat genes.

J. Clin. Invest.

(c) The American Society for Clinical Investigation, Inc.

0021-9738/91/08/0540/06 \$2.00

Volume 88, August 1991, 540-545 be primarily responsible for viral replication due to the presence of two repeated NF $\kappa$ B binding domains within the HIV-1 promoter (5-9), although additional promoter elements have been described (10-12). Activation by cytokines, particularly TNF- $\alpha$, has also been demonstrated to result in enhancement of HIV replication and induction of $\mathrm{NF}_{\kappa} \mathrm{B}$ (13-16).

Unlike CD4+ $T$ lymphocytes, macrophages sustain prolonged periods of infection by HIV with significantly less cytopathology and cell death (17-20). The mechanisms underlying these differences remain unknown. Studies with the promonocytic U937 and monocytic THP-1 (21-24) cell lines have demonstrated that activation using LPS or TNF- $\alpha$ resulted in enhanced HIV replication, a process that correlated with activation of $N_{K} B$ (24). Although mature monocytes and macrophages were shown to express $\mathrm{NF}_{\kappa} \mathrm{B}$ constitutively (6), the effects of stimulation of mature primary monocyte-derived macrophages on HIV replication have not been systematically assessed. The data presented here suggest that these cells, unlike $\mathrm{T}$ lymphocytes or monocytoid cell lines that undergo replication, down-regulate HIV expression after cellular activation.

\section{Methods}

Cell culture. Macrophages were derived from peripheral blood monocytes as previously described (25). Mononuclear cells from normal blood donors were separated over Ficoll-Hypaque gradients, washed, suspended in RPMI 1640 supplemented with antibiotics, $10 \%$ heat-inactivated FCS, and 5\% heat-inactivated, HIV- and HBV-seronegative, pooled human AB serum (Gemini Bioproducts, Inc., Calabasas, $\mathrm{CA}$ ), and incubated in 150-mm polystyrene dishes for $3 \mathrm{~h}$. Dishes were washed with warm HBSS to remove nonadherent cells and repleted with fresh media. The following day, plates were washed extensively, covered with cold $\mathrm{Ca}^{++}, \mathrm{Mg}^{++}$free $\mathrm{HBSS}$, placed on ice, and scraped to recover the adherent cell population. Cells were washed, resuspended in RPMI containing 10\% human serum and 5\% FCS, and placed in polytetrafluorethylene (Teflon; Savillex Corp., Minneapolis, MN) jars at a concentration of $1 \times 10^{6}$ cells $/ \mathrm{ml}$. Cells were maintained in suspension culture with media changed at 5-7-d intervals. Experiments were conducted on individual donors that were maintained in separate suspension cultures. In designated experiments, monocytes were purified by adherence and scraping on the day they were obtained from donors, and used immediately in transfection experiments. In selected experiments, macrophages cultured long-term were further purified by complement depletion of contaminating T lymphocytes. Cells $\left(1.5 \times 10^{7}\right)$ were incubated at $4^{\circ} \mathrm{C}$ for $1 \mathrm{~h}$ with anti-CD2 (Anti-Leu-5b, mouse $\mathrm{IgG}_{2 \mathrm{a}}$; Becton-Dickinson Co., Mountain View, CA) and anti-CD3 (OKT 3, mouse $\mathrm{IgG}_{2 \mathrm{a}}$; American Type Culture Collection, Rockville, MD) monoclonal antibodies, washed, and incubated at $37^{\circ} \mathrm{C}$ for $1 \mathrm{~h}$ with rabbit complement (Cedarlane, Ontario, Canada). Cell preparations were $>92 \%$ macrophages and $<0.5 \% \mathrm{~T}$ lymphocytes as assessed by fluorescence (anti-CD14, anti-CD3 monoclonal antibodies; BectonDickinson Co.) and size analysis (FACScan; Becton-Dickinson Co.).

Promonocytic U937 cells were grown in RPMI 1640 supplemented with antibiotics and $10 \%$ heat-inactivated FCS. The cells were differentiated to a nondividing, macrophagelike phenotype by incubation in 
$100 \mathrm{ng} / \mathrm{ml}$ phorbol 12-myristate 13-acetate (PMA; Sigma Chemical Co., St. Louis, MO) for $72 \mathrm{~h}$. The cells, which were loosely adherent, were collected after brief incubation in cold, $\mathrm{Ca}^{++} \mathbf{M g}^{++}$-free media.

Cell culture reagents contained $<10 \mathrm{pg} / \mathrm{ml}$ of detectable endotoxin as assessed using the limulus amebocyte lysate assay (Sigma Chemical Co., St. Louis, MO).

Plasmid constructions. The LTR-CAT plasmid contains the HIV-1 LTR derived from $\mathrm{HIV}_{\mathrm{SF} 2}$ positioned upstream of the chloramphenicol acetyltransferase (CAT) gene (26). TAT is a plasmid containing the synthetic HIV SF2 $_{\text {tat }}$ gene positioned downstream of the SV40 early promoter (26). pKBm-CAT (gift of Dr. G. Nabel, University of Michigan, Ann Arbor, MI) contains substitution mutations of three nucleotides in each $\mathrm{NF}_{\kappa} \mathrm{B}$ binding domain of the HIV-1 enhancer precluding $\mathrm{NF}_{\kappa} \mathrm{B}$ binding (13). Plasmids $p-156 /+185$ CAT (4) and $p-121 /+232$ CAT (gift of Dr. D. Capon, Genentech, Inc., South San Francisco, CA) (27) are $5^{\prime}$ deletion mutants of the HIV LTR. Plasmid pCH1 10 contains the Escherichia coli lac $\mathrm{Z}$ gene, encoding $\beta$-galactosidase, expressed by the SV-40 early promoter (Pharmacia, Inc., Piscataway, NJ). Plasmid pHIV lac $Z$ contains the HIV-1 LTR positioned upstream of the $E$. coli lac $Z$ gene (gift of Dr. Joseph Maio, AIDS Research and Reference Reagent Program, NIAID, NIH) (28). pCAT-Control contains the CAT gene positioned downstream of the SV-40 early promoter and enhancer (Promega Biotec, Madison, WI)

Transfections and LPS stimulation. Fresh monocytes or monocytederived macrophages (12-14 $\mathrm{d}$ in suspension culture) from individual donors were transfected by electroporation using a Bio-Rad Gene Pulser (Bio-Rad Laboratories, Richmond, CA). For each transfection, $250 \mu \mathrm{l}$ cells at a concentration of $1.3 \times 10^{7}$ cells $/ \mathrm{ml}$ were combined with $40 \mu \mathrm{g} / \mathrm{ml}$ of each plasmid indicated and subjected to $300 \mathrm{~V}$ at $960 \mu \mathrm{F}$ in cuvettes with pre- and postelectroporation incubations on ice for 10 min. After transfection, cells were diluted in fresh culture media (RPMI 1640 with $10 \%$ human serum, 5\% FBS, and antibiotics) to a density of $10^{6} \mathrm{cells} / \mathrm{ml}$ and incubated $24 \mathrm{~h}$ in the absence or presence of LPS (E. coli 055:B5; Sigma Chemical Co.) in $5 \% \mathrm{CO}_{2}$ at $37^{\circ} \mathrm{C}$. In each experiment, cells transfected with identical plasmids were either electroporated in one cuvette or mixed before LPS exposure to eliminate transfection efficiency as a determinant of CAT activity. U937 cells in logarithmic growth phase were transfected with LTR-CAT and TAT in similar fashion except that media contained $10 \%$ FBS and no human serum.

CAT assays. Cells were harvested and lysed, and CAT activity was determined according to standard methods (29). Assays were performed in a $200-\mu$ l volume containing $0.1 \mu \mathrm{Ci}(3.7 \mathrm{kBq}){ }^{14} \mathrm{C}$-chloramphenicol, $4 \mathrm{mM}$ acetyl-coenzyme A, $0.25 \mathrm{M}$ Tris- $\mathrm{HCl}$ (pH 7.4), and an appropriate amount of cell lysate. Protein concentration of the cel extracts was quantitated using the Bradford assay (30) (Bio-Rad Laboratories, Inc., Richmond, CA) and used to normalize the quantity of lysate added within a single experiment. CAT activity was determined by measuring the amount of ${ }^{14} \mathrm{C}$-chloramphenicol converted to acetylated chloramphenicol after separation by thin layer chromatography. Conversion was quantitated by liquid scintillation counting. Experiments were repeated as necessary adjusting protein concentration and duration of incubation to maintain acetylation in the linear range.

Transfections were performed between three and 10 times and results are reported as either representative experiments or as the arithmetic mean of differences in acetylation \pm SEM

Assay for $\beta$-galactosidase in situ. Cells were transfected with constructs containing the lac $Z$ reporter gene using the same methods of electroporation. Cells were incubated for $24 \mathrm{~h}$ and spun onto microscope slides using a Cytospin cytocentrifuge (Shandon, Inc., Pittsburg, PA). Slides were fixed in 50\% vol/vol acetone:methanol, air dried, and stained with a solution composed of $1 \mathrm{mg} / \mathrm{ml} 5$-bromo-4-chloro 3-indoyl- $\beta$-D-galactopyranoside (X-gal), $3.3 \mathrm{mM}$ potassium ferricyanide, $3.3 \mathrm{mM}$ potassium ferrocyanide, and $1.5 \mathrm{mM}$ magnesium chloride in PBS, pH 7.4. Slides were incubated $24-48 \mathrm{~h}$ in a $37^{\circ} \mathrm{C}$ humidified $5 \%$ $\mathrm{CO}_{2}$ incubator and examined by microscopy. Blue-colored cells were counted microscopically to determine transfection efficiency. Cells stained for $\beta$-galactosidase expression were further counterstained with $\alpha$-naphthyl acetate esterase (kit No. 91-A, Sigma Chemical Co.) which produces dark granules specifically in monocyte-macrophages.

HIV infection of macrophages and LPS stimulation. After $3 \mathrm{~d}$ in suspension culture, macrophages were infected with HIV-1 strain, $\mathrm{HIV}_{\mathrm{DV}}$, at a multiplicity of one $\left(1 \times 10^{6} 50 \%\right.$ tissue culture infective doses $/ \mathrm{ml}$ ) for $48 \mathrm{~h}$, washed, and incubated in fresh media as described (25). At day 13, equivalent numbers of infected macrophages from a single donor were placed in media containing $1 \mu \mathrm{g} / \mathrm{ml}$ LPS or control media for $5 \mathrm{~h}$, washed extensively, and resuspended in fresh media. At 24 or $96 \mathrm{~h}$, cell-free culture supernatants were harvested and assayed for HIV p24 core antigen by ELISA (DuPont Co., Wilmington, DE). Supernatants were also assayed for infectivity by a limiting dilution syncytia assay using the T-cell lymphoma line VB (31). Briefly, $2 \times 10^{4}$ VB cells in a $100-\mu l$ volume were added to wells of 96-well culture plates. Cell-free supernatants were added to VB cells in threefold dilution to $3^{-8}$, with each dilution assayed in triplicate. Wells were visually scored for the presence of syncytia after 5-7 d.

\section{Results}

$H I V-1$ LTR-directed gene expression in primary monocyte-derived macrophages. After 10-14 d in culture, monocyte-derived cells expressed the phenotype of mature macrophages and were in the resting state as assessed by the absence of IL-1 or TNF protein in the media and the absence of IL-1 mRNA as measured by Northern analysis (25). Conditions necessary to optimize transient transfections by electroporation were first established by varying voltage and capacitance during electroporation. A constitutively expressed SV-40 promoter- $\beta$-galactosidase construct was used to allow the direct visualization of transfected cells by staining for $\beta$-galactosidase and counterstaining with $\alpha$-naphthyl acetate esterase, a monocyte-macrophage marker. Under the conditions described $(300 \mathrm{~V}, 960 \mu \mathrm{F}$; Methods), $\sim$ 1:500-1:1,000 cells expressed $\beta$-galactosidase after transfection, and all transfected cells expressed the macrophage esterase marker and had the typical morphology of macrophages (data not shown). These experiments demonstrated the ability to establish consistent SV-40-directed gene expression in primary macrophages. Tat, the HIV-1 transactivating protein, has been demonstrated to stabilize message elongation and increase transcriptional initiation by the $\operatorname{LTR}(1,2)$. An SV-40-tat construct was cotransfected with a plasmid containing the HIV-1 LTR upstream of the $\beta$-galactosidase gene (pHIV lac $Z$ ) to test transfection efficiency in macrophages under these conditions. When cotransfected with an SV-40-tat construct, $\sim 1: 150-1: 300$ cells expressed $\beta$-galactosidase driven by the HIV LTR, as assessed by direct microscopic examination.

Monocyte-derived macrophages were transfected using HIV-1 LTR-CAT gene constructs using the same conditions. Cotransfection using a plasmid encoding tat expressed by the SV-40 early promoter was performed where designated to optimize CAT activity. After transfection, macrophages were incubated in media alone or in the indicated amounts of LPS for 24 $h$, harvested by centrifugation, lysed, and assayed for CAT activity. In some experiments, 14-d cultured macrophages were subjected to two cycles of incubation with anti-CD2 and antiCD3 monoclonal antibodies plus complement before transfection; analysis of these cell preparations by FACS demonstrated that $92-96 \%$ of cells were macrophages as assessed by size, staining for CD14 and nonspecific esterase, and the absence of $T$ cells as assessed by anti-CD3,-CD4, and -CD8 staining. Transfection of these highly purified macrophages resulted in 
marked transactivation by tat and almost complete suppression of HIV-directed CAT expression by LPS (Fig. 1). Basal HIV-LTR-directed CAT activity varied among donors, although cotransfection with tat consistently resulted in augmented CAT expression that ranged from 3- to 10-fold. Comparable results were obtained in donors in which complement depletion was not used to remove $T$ lymphocytes remaining at $14 \mathrm{~d}$ in culture. Whether the HIV-LTR-CAT was transfected alone or with SV-40-tat, however, LPS down-regulated CAT activity in all donors, and a dose-dependent relationship could be demonstrated (Fig. 2). In 10 individual transfections of different donor cells, $1 \mu \mathrm{g} / \mathrm{ml}$ LPS decreased LTR-directed CAT expression $42 \pm 8.3 \%$ (mean \pm SEM). Incubation in LPS had no effect on CAT expression in macrophages transfected with a constitutively expressed SV-40-CAT plasmid (data not shown).

Fresh monocytes were transfected the same day they were prepared from donors with the HIV-LTR-CAT and SV-40-tat plasmid constructs and assayed using the same conditions. In contrast to the cultured macrophages, fresh monocytes increased LTR-directed CAT expression after activation with LPS by a mean of 3.55 -fold \pm 0.43 (Fig. 3 ).

LTR-directed gene expression in U937 cells. Prior investigations have documented that increased viral production occurs after activation of macrophagelike cell lines, including U937 and THP-1 (21-24). In agreement with these reports, stimulation of U937 cells cotransfected with the HIV-LTRCAT and SV-40-tat constructs using LPS resulted in a dose-dependent increase in CAT activity (Fig. 4). In five transfections, a $1 \mu \mathrm{g} / \mathrm{ml}$ dose of LPS induced an $8.8 \pm 1.4$-fold (mean \pm SEM) increase in CAT activity. U937 cells were next transfected with these constructs using the same conditions $3 \mathrm{~d}$ after incubation with PMA. Such treatment resulted in cessation of growth as assessed by the failure to incorporate ${ }^{3} \mathrm{H}$-thymidine (data not shown) and the acquisition of a mature phenotype as described $(6,32,33)$. In contrast to resting U937 cells, the differentiated U937 cells responded to LPS activation by down-regulation of CAT activity mediated by the HIV LTR (Fig. 4). In three transfections, the mean decrease in CAT activity after LPS incubation was $39 \pm 6.4 \%$ (mean \pm SEM). Addition of PMA to undifferentiated U937 cells immediately before transfection did not abrogate the upregulation of LTR-directed CAT expression.

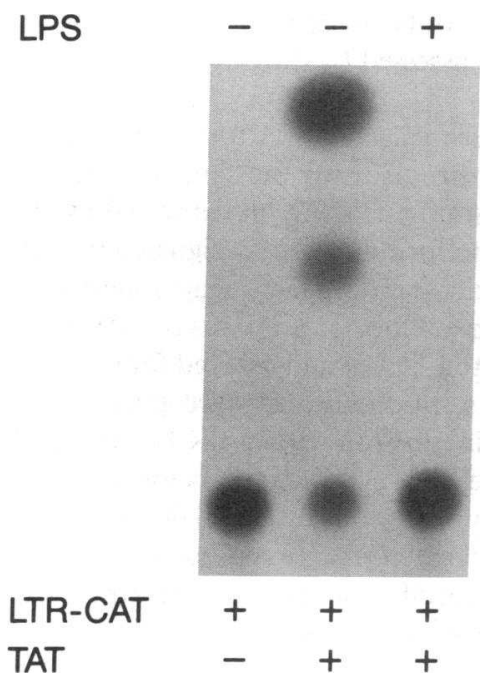

Figure 1. LPS decreases HIV-LTR-directed gene expression in macrophages. Monocyte-derived macrophages were transfected with plasmids containing HIV-LTR-CAT or with SV40-TAT and incubated $24 \mathrm{~h}$ in the absence or presence of $1 \mu \mathrm{g} / \mathrm{ml}$ LPS. Cell lysates were harvested and assayed for CAT activity by thin layer chromatography. This experiment is representative of comparable transfections using three different donors.

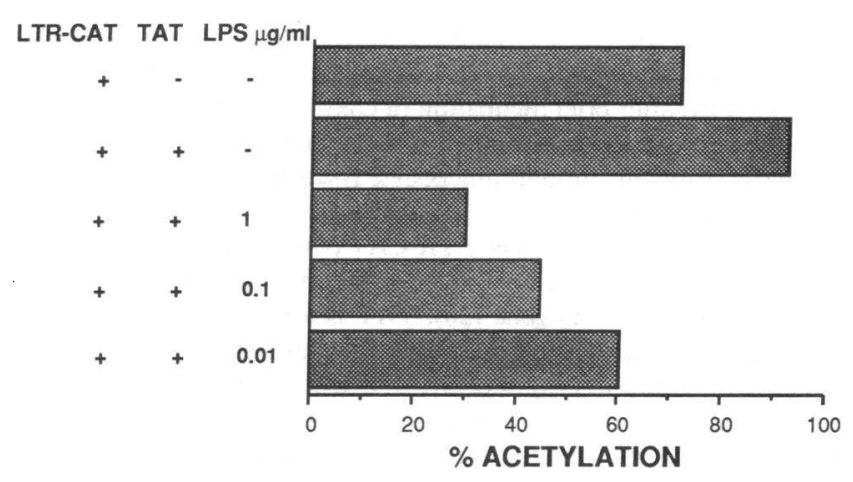

Figure 2. Dose-response inhibition of HIV-LTR-directed gene expression by LPS. Monocyte-derived macrophages were transfected with HIV-LTR-CAT and SV40-TAT constructs and incubated in LPS over a dose range of 1 to $0.01 \mu \mathrm{g} / \mathrm{ml}$. CAT activity is expressed graphically as percent acetylation of ${ }^{14} \mathrm{C}$-chloramphenicol after separation by thin layer chromatography and scintillation counting. The experiment shown is representative of three comparable transfections from different donors.

Mapping the LPS-responsive element with mutated LTR constructs. A series of $5^{\prime}$ deletion constructs of the HIV LTR linked to CAT was used to map the LPS-responsive element (Fig. 5). The mutated constructs were co-transfected with the SV40-TAT plasmid into 14-d cultured macrophages and CAT activity measured after incubation with or without LPS. Although the $-156 /+185$ construct maintained the LPS response, $a-121 /+232$ construct resulted in loss of negative regulation, suggesting that the LPS responsive sequences lie between nucleotides -156 and -121 in the viral LTR. A construct containing substitution mutations within both $\mathrm{NF}_{\kappa} \mathrm{B}$ binding sites in the HIV enhancer still responded to negative regulation by LPS. CAT expression in cells transfected with LTR-CAT alone (Fig. 5, lanes 1 and 2) or cotransfected with SV40-TAT (Fig. 5, lanes 3 and 4 ) were both decreased by $57 \%$, indicating that the LPS effect is independent of tat.

$L P S$ regulation of whole virus production in macrophages. To assess the capacity of macrophage stimulation by LPS to negatively regulate whole virus production, monocyte-derived macrophages were infected with HIV-1 as previously described

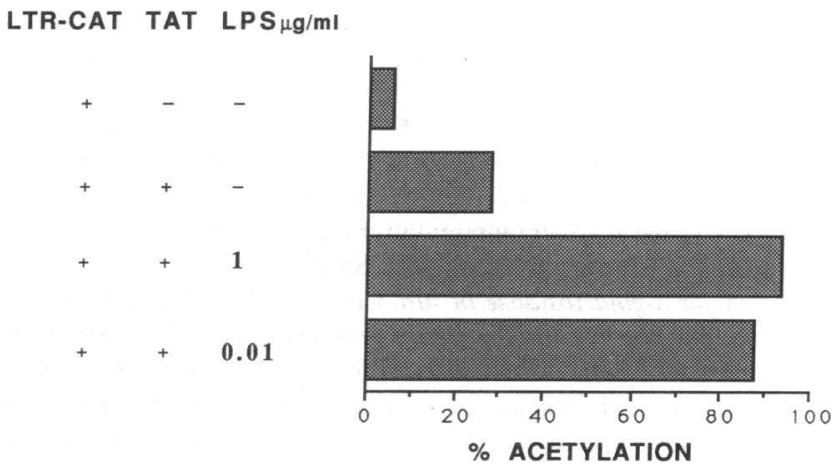

Figure 3. LPS enhancement of HIV-LTR-directed gene expression in fresh monocytes. Freshly purified peripheral blood monocytes were transfected with HIV-LTR-CAT and SV40-TAT constructs and incubated in LPS at concentrations shown. CAT activity was assayed after $24 \mathrm{~h}$ incubation. The experiment shown is representative of three transfections from different donors. 


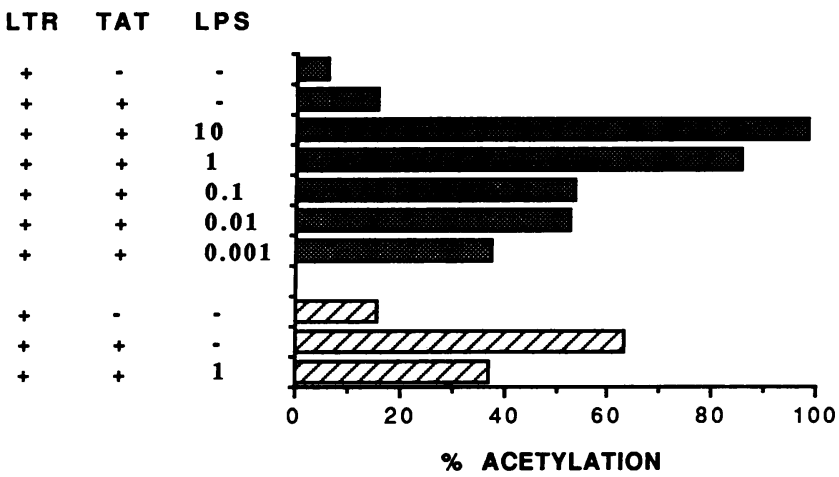

Figure 4. LPS regulation of HIV-LTR-directed gene expression in nondifferentiated and PMA-differentiated U937 cells. Nondifferentiated ( $\square$ ) or differentiated, mature, nondividing (四) U937 cells (Methods) were transfected with HIV-LTR-CAT (LTR) and SV40TAT (TAT) constructs and incubated in LPS over a dose range of 10 to $0.001 \mu \mathrm{g} / \mathrm{ml}$. CAT activity after $24 \mathrm{~h}$ incubation was determined following chromatography and scintillation counting and is expressed as percent acetylation. The experiment is representative of five independent transfections.

(25) and maintained in culture for 10-14 d. Cells were washed and incubated in media alone or with $1 \mu \mathrm{g} / \mathrm{ml}$ LPS for $5 \mathrm{~h}$, washed extensively, and resuspended in fresh media. Immediately after washing, supernatant p24 assayed by ELISA was $<0.8 \mathrm{ng} / \mathrm{ml}$ and was comparable between control and LPS-stimulated cells (Fig. 6). 24 or $96 \mathrm{~h}$ after incubation, cells treated with LPS-containing media released $\sim 50 \%$ less p24 antigen than matched cells incubated in control media. Comparable results were obtained in experiments from eight individual do-

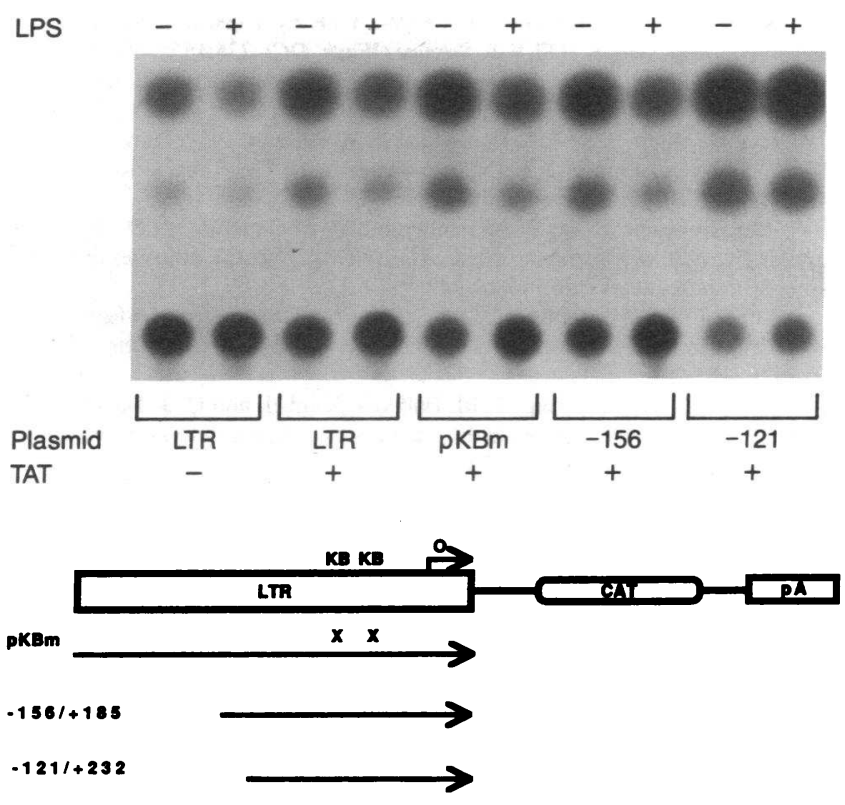

Figure 5. Transfection of macrophages with mutated HIV-LTR constructs. The schematic below the figure depicts the full-length HIVLTR-CAT plasmid and the mutated plasmid constructions. Plasmid pKBm has mutations in both NFKB binding sites, plasmids -156/ +185 and $-121 /+232$ are $5^{\prime}$ deletions of the LTR. Macrophages were transfected with the designated plasmids and divided into equal aliquots that were incubated with or without $1 \mu \mathrm{g} / \mathrm{ml}$ LPS for $24 \mathrm{~h}$. The transfection shown is representative of three independent experiments using different donors.

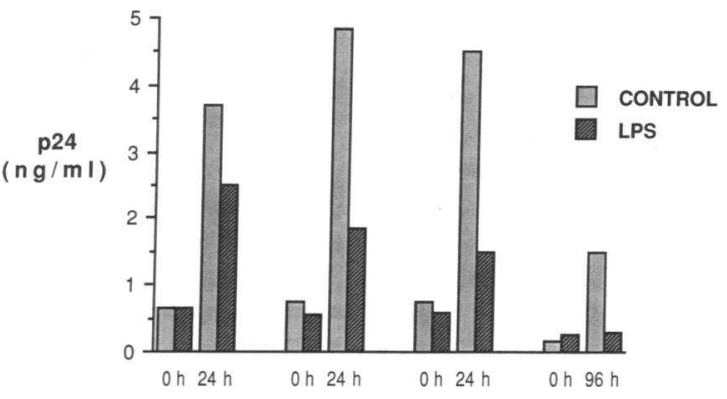

Figure 6. Effect of LPS activation on viral p24 production by HIVinfected macrophages. Monocyte-derived macrophages infected with HIV for 2 wk were washed and equivalent numbers of cells from single donors were placed in media with or without $1 \mu \mathrm{g} / \mathrm{ml} \mathrm{LPS} \mathrm{for}$ $5 \mathrm{~h}$, washed, and resuspended in fresh media. At 0,24 , or $96 \mathrm{~h}$, cell free culture supernatants were harvested and assayed for HIV p24 core antigen by ELISA. Four of eight comparable experiments using different donor macrophages are depicted.

nors with a mean decrease in p24 antigen of $53 \pm 7 \%$. There was no toxicity to macrophages exposed to LPS as assessed by trypan blue staining. Virus produced by the infected macrophages was fully infectious for T cell lines. Supernatants obtained 24$96 \mathrm{~h}$ after incubation from six of the same donors were assayed quantitatively for infectivity using a limiting dilution syncytia forming assay. Supernatants from the six pairs of infected macrophages were three- to fourfold more infectious (mean, $3.67 \pm 0.67)$ by syncytia formation after incubation in media alone than following exposure to LPS.

\section{Discussion}

The data presented indicate that mature, monocyte-derived macrophages can be studied for regulation of HIV gene expression by transient transfection assays and that these cells appear to down-regulate LTR-directed expression in response to activation by LPS. In contrast, freshly isolated monocytes up-regulated LTR-directed gene expression after exposure to LPS. In agreement with the findings of other investigators (24), LPS was a potent stimulator of HIV gene expression in promonocytic U937 cells, similar to the enhancement observed in T cells after activation. However, when U937 cells were differentiated to a mature, nondividing phenotype, LPS activation resulted in down-regulation of LTR-directed gene expression comparable to that observed in macrophages. These findings suggest that the capacity of HIV to use cell activation signals to enhance viral replication may correlate with the maturational phenotype of the cell and/or the ability of the cell to enter a replicative cycle.

T lymphocytes activated through the antigen receptor (1-4) and monocyte cell lines stimulated with bacterial LPS (24) enhance HIV replication primarily by the activation of the cellular transcription factor NFאB. Monocyte-macrophages do not divide significantly after activation, and thus differ from lymphocytes or surrogate cell lines like U937 or THP-1. As shown here using transient transfections of primary monocyte-derived macrophages, stimulation of these cells with LPS resulted in consistent down-regulation of HIV-LTR-directed CAT gene expression. Transfection of these cells by electroporation resulted in a transfection efficiency of 1:150-1:300 cells, and whether extrapolation to the entire population of macrophages 
is warranted is not known. The fact that comparable results were obtained in transfections from 10 different donors and that similar levels of down-regulation $(\sim 50 \%)$ occurred in the release of p24 antigen from cells infected 10-14 d with whole virus, suggests that this is a general and reproducible phenomenon in macrophages. Further, the disparate results using U937 cells in either the undifferentiated or differentiated state paralleled the results using fresh monocytes or cultured macrophages and suggests that cellular regulators of transcription available to the virus may differ significantly depending on the maturational state of the cell. The reports that macrophage growth factors such as GM-CSF, M-CSF, and IL-3 may enhance HIV replication in mononuclear phagocytes (34) suggests that activation of replication pathways in these cells may also be associated with viral stimulation. Similarly, myeloid progenitor cells from normal human bone marrow are readily infected with HIV in vitro (35) and bone marrow samples from AIDS patients have demonstrated highest levels of HIV gene expression in myeloid precursor cells (36).

The disparate regulation of viral gene expression after activation of mature mononuclear phagocytes as compared with lymphocytes may be relevant to the capacity of macrophages to resist cytopathic effects of HIV and act as a prolonged reservoir for virus. Macrophages with suppressed viral production may be able to escape recognition and destruction by immune defenses. Recent evidence suggests that these cells maintain their function as antigen presenting cells, which may be important in the direct transmission of HIV to CD4+ T cells (37). It remains unknown whether induction of cytokines from macrophages by LPS may indirectly mediate or contribute to the observed negative regulation. Interferon- $\alpha$ has been shown to restrict HIV expression in infected monocytes (38), whereas IL- 6 and TNF- $\alpha$ positively regulated HIV expression in monocytic cell lines (39), and functioned in an autocrine or paracrine fashion to augment virus production by infected $\mathrm{T}$ lymphocytes (14-16, 22, 39). The capacity for LPS to up-regulate HIV expression in U937 and THP-1 cell lines was demonstrated to occur comparably in the absence or presence of neutralizing anti-TNF antibody, suggesting that LPS independently activates cellular NF $\kappa$ B (24). The effects of cytokines or cytokine antibodies in modulating the effects reported here will require further investigation.

Prior studies by others have reported the ability of pretreatment with LPS to induce a nonpermissive state in macrophages subsequently exposed to HIV (40). The studies reported here demonstrate that activation of chronically infected macrophages results in a decrease in viral replication that was comparable in magnitude to a direct negative effect on the HIV promoter as assessed in a transient transfection assay. The negative regulation by LPS was independent of tat, and could be mapped to a 35-nucleotide region in the HIV LTR. This area is at the 3 ' boundary of a previously described negative regulatory element $(1,41,42)$ and adjacent to an 11 nucleotide sequence capable of binding a cellular $50-\mathrm{kD}$ protein that serves as a transcriptional silencer (43). Mikovits et al. recently reported a subset of HIV-infected monocytic THP-1 cells that demonstrated restricted HIV expression apparently due to blocking of DNA binding complex formation with the LTR, thus interfering with transcription initiation (23). This effect may be due to active repression by a novel DNA-binding factor and was not seen in cells with true latent infection.

Decreased HIV-1 gene expression after LPS-induced acti- vation could be mediated by stabilization of transcriptional repressors, induction of additional negative binding elements, or decreased production of enhancers of transcription. More complex mechanisms by which positive or negative regulatory effects may be evoked from a specific DNA sequence have recently been elucidated (44). Protein-protein interactions between transcriptional regulatory factors in addition to DNA binding effects may permit opposite outcomes on gene expression after exposure to a given extracellular stimulus, depending on the phenotypic context of the cell. The differential responses to LPS activation by monocytes and macrophages or by undifferentiated and differentiated U937 cells may provide a model to investigate the restricted expression of HIV-1 observed in monocyte/macrophages and contribute to our understanding of the long period of disease latency observed after this infection.

\section{Acknowledgments}

The authors gratefully acknowledge the skilled technical assistance of D. Kobashigawa, M. Hu, and A. Acevedo, referral of blood donors by Dr. Catherine Koo and Dr. John Boggs, and the thoughtful comments of Dr. B. M. Peterlin and Dr. J. A. Levy.

The following reagent was obtained through the AIDS Research and Reference Reagent Program, Division of AIDS, National Institute of Allergy and Infectious Diseases, National Institutes of Health (NIH): pHIVlacZ from Dr. Joseph Maio. This work was supported by the State of California through the Universitywide Task Force on AIDS, the American Foundation for AIDS Research, NIH DK41059, and an AIDS New Investigator Grant from the San Francisco Center for AIDS Research.

\section{References}

1. Siekevitz, M., S. F. Josephs, M. Dukovich, N. Peffer, F. Wong-Staal, and W. C. Greene. 1987. Activation of the HIV-1 LTR by T cell mitogens and the trans-activator protein of HTLV-1. Science (Wash. DC). 238:1575-1578.

2. Cullen, B. R., and W. C. Greene. 1989. Regulatory pathways governing HIV-1 replication. Cell. 58:423-426.

3. Tong-Starksen, S. E., P. A. Luciw, and B. M. Peterlin. 1987. Human immunodeficiency virus long terminal repeat responds to $\mathrm{T}$-cell activation signals. Proc. Natl. Acad. Sci. USA. 84:6845-6849.

4. Tong-Starksen, S. E., P. A. Luciw, and B. M. Peterlin. 1989. Signaling through T lymphocyte surface proteins, TCR/CD3 and CD28, activates the HIV1 long terminal repeat. J. Immunol. 142:702-707.

5. Nabel, G., and D. Baltimore. 1987. An inducible transcription factor activates expression of human immunodeficiency virus in T cells. Nature (Lond.) 326:711-713.

6. Griffin, G. E., K. Leung, T. M. Folks, S. Kunkel, and G. J. Nabel. 1989. Activation of HIV gene expression during monocyte differentiation by induction of NFKB. Nature (Lond.) 339:70-73.

7. Kawakami, K., C. Scheidereit, and R. G. Roeder. 1988. Identification and purification of a human immunoglobulin-enhancer-binding protein $\left(\mathrm{NF}_{\kappa} \mathrm{B}\right)$ that activates transcription from a human immunodeficiency virus type 1 promoter in vitro. Proc. Natl. Acad. Sci. USA. 85:4700-4704.

8. Bielinska, A., S. Krasnow, and G. J. Nabel. 1989. NF-kB-mediated activation of the human immunodeficiency virus enhancer: site of transcriptional initiation is independent of the TATA box. J. Virol. 63:4097-4100.

9. Bohnlein, E., J. W. Lowenthal, M. Siekevitz, D. W. Ballard, B. R. Franza, and W. C. Greene. 1988. The same inducible nuclear protein regulates mitogen activation of both the interleukin-2 receptor-alpha gene and type 1 HIV. Cell. 53:827-836

10. Nabel, G. J., S. A. Rice, D. M. Knipe, and D. Baltimore. 1988. Alternative mechanisms for activation of human immunodeficiency virus enhancer in $T$ cells. Science (Wash. DC). 239:1299-1302.

11. Garcia, K. A., F. K. Wu, R. Mitsuyasu, and R. B. Gaynor. 1987. Interactions of cellular proteins involved in the transcriptional regulation of the human immunodeficiency virus. EMBO (Eur. Mol. Biol. Org.) J. 6:3761-3770.

12. Jones, K. A. 1989. HIV trans-activation and transcription control mechanisms. The New Biologist. 1:127-135.

13. Osborn, L., S. Kunkel, and G. J. Nabel. 1989. Tumor necrosis factor $\alpha$ and interleukin 1 stimulate the human immunodeficiency virus enhancer by activation of the nuclear factor $\kappa$ B. Proc. Natl. Acad. Sci. USA. 86:2336-2340. 
14. Folks, T. M., K. A. Clouse, J. Justement, A. Rabson, E. Duh, J. H. Kehrl, and A. S. Fauci. 1989. Tumor necrosis factor $\alpha$ induces expression of human immunodeficiency virus in a chronically infected T-cell clone. Proc. Natl. Acad. Sci. USA. 86:2365-2368.

15. Duh, E. J., W. J. Maury, T. M. Folks, A. S. Fauci, and A. B. Rabson. 1989. Tumor necrosis factor $\alpha$ activates human immunodeficiency virus type 1 through induction of nuclear factor binding to the NF $\kappa$ B sites in the long terminal repeat. Proc. Natl. Acad. Sci. USA. 86:5974-5978.

16. Israel, N., U. Hazan, J. Alcami, A. Munier, F. Arenzana-Seisdedos, F. Bachelerie, A. Israel, and J.-L. Virelizier. 1989. Tumor necrosis factor stimulates transcription of HIV-1 in human T lymphocytes, independently and synergistically with mitogens. J. Immunol. 143:3956-3960.

17. Ho, D. D., T. R. Rota, and M. S. Hirsch. 1986. Infection of monocyte/ macrophages by human T lymphotropic virus type III. J. Clin. Invest. 77:17121715 .

18. Gartner, S., P. Markovits, D. M. Markovitz, M. H. Kaplan, R. C. Gallo, and M. Popovic. 1986. The role of mononuclear phagocytes in HTLV-III/LAV infection. Science (Wash. DC). 233:215-219.

19. Gendelman, H. E., J. M. Orenstein, M. A. Martin, C. Ferrua, R. Mitra, T. Phipps, L. A. Wahl, H. C. Lane, A. S. Fauci, D. S. Burke, D. Skillman and M. S. Meltzer. 1988. Efficient isolation and propagation of human immunodeficiency virus on recombinant colony-stimulating factor 1-treated monocytes. J. Exp. Med. 167:1428-1441.

20. Collman, R., N. F. Hassan, R. Walker, B. Godfrey, J. Cutilli, J. C. Hastings, H. Friedman, S. D. Douglas, and N. Nathanson. 1989. Infection of monocyte-derived macrophages with human immunodeficiency virus type 1 (HIV-1). J. Exp. Med. 170:1149-1163.

21. Molina, J.-M., D. T. Scadden, R. Byrn, C. A. Dinarello, and J. E. Groopman. 1989. Production of tumor necrosis factor $\alpha$ and interleukin $1 \beta$ by monocytic cells infected with human immunodeficiency virus. J. Clin. Invest. 84:733737.

22. Poli, G., A. Kinter, J. S. Justement, J. H. Kehrl, P. Bressler, S. Stanley, and A. S. Fauci. 1990. Tumor necrosis factor $\alpha$ functions in an autocrine manner in the induction of human immunodeficiency virus expression. Proc. Natl. Acad. Sci. USA. 87:782-785.

23. Mikovits, J. A., Raziuddin, M. Gonda, M. Ruta, N. C. Lohrey, H.-F. Kung, and F. W. Ruscetti. 1990. Negative regulation of human immune deficiency virus replication in monocytes. J. Exp. Med. 171:1705-1720.

24. Pomerantz, R. J., M. B. Feinberg, D. Trono, and D. Baltimore. 1990 Lipopolysaccharide is a potent monocyte/macrophage-specific stimulator of human immunodeficiency virus type 1 expression. J. Exp. Med. 172:253-261.

25. Locksley, R. M., S. Crowe, M. D. Sadick, F. P. Heinzel, K. D. Gardner, M. S. McGrath, and J. Mills. 1988. Release of interleukin 1 inhibitory activity (contra-IL-1) by human monocyte-derived macrophages infected with human immunodeficiency virus in vitro and in vivo. J. Clin. Invest. 82:2097-2105.

26. Peterlin, B. M., P. A. Luciw, P. J. Barr, and M. D. Walker. 1986. Elevated levels of mRNA can account for the trans-activation of human immunodef ciency virus. Proc. Natl. Acad. Sci. USA. 83:9734-9738.

27. Muesing, M. A., D. H. Smith, and D. J. Capon. 1987. Regulation of mRNA accumulation by a human immunodeficiency virus trans-activator protein. Cell. 48:691-701.

28. Maio, J. J., and F. L. Brown. 1988. Regulation of expression driven by human immunodeficiency virus type 1 and human T-cell leukemia virus type long terminal repeats in pluripotential human embryonic cells. J. Virol. 62:1398 1407.
29. Gorman, C. M., L. F. Moffat, and B. H. Howard. 1982. Recombinan genomes which express chloramphenicol acetyltransferase in mammalian cells. Mol. Cell. Biol. 2:1044-1051.

30. Bradford, M. M. 1976. A rapid and sensitive method for the quantitation of microgram quantities of protein using the principle of protein-dye binding. Anal. Biochem. 72:248-254.

31. Lifson, J. D., G. R. Reyes, M. S. McGrath, B. S. Stein, and E. G. Engleman. 1986. AIDS retrovirus induced cytopathology: giant cell formation and involvement of CD4 antigen. Science (Wash. DC). 232:1123-1127.

32. Moscicki, R. A., E. P. Amento, S. M. Krane, J. T. Kurnick, and R. B. Colvin. 1983. Modulation of surface antigens of a human monocyte cell line, U937, during incubation with $T$ lymphocyte-conditioned medium: detection of T4 antigen and its presence on normal blood monocytes. J. Immunol. 131:743748.

33. Mitchell, R. L., C. Henning-Chubb, E. Huberman, and I. M. Verma 1986. c-fos expression is neither sufficient nor obligatory for differentiation of monomyelocytes to macrophages. Cell. 45:497-504.

34. Koyanagi, Y., W. A. O'Brien, J. Q. Zhao, D. W. Golde, J. C. Gasson, and I. S. Y. Chen. 1988. Cytokines alter production of HIV-1 from primary mononuclear phagocytes. Science (Wash. DC). 241:1673-1675.

35. Folks, T. M., S. W. Kessler, J. M. Orenstein, J. S. Justement, E. S. Jaffe, and A. S. Fauci. 1988. Infection and replication of HIV-1 in purified progenitor cells of normal human bone marrow. Science (Wash. DC). 242:919-922.

36. Busch, M., J. Beckstead, D. Gantz, and G. Vyas. 1986. Detection of human immunodeficiency virus infection of myeloid precursors in bone marrow samples from AIDS patients. Blood. 68(Suppl. 1):122a. (Abstr.)

37. Mann, D. L., S. Gartner, F. L. Sane, H. Buchow, and M. Popovic. 1990. HIV-1 transmission and function of virus-infected monocytes/macrophages. $J$. Immunol. 144:2152-2158.

38. Gendelman, H. E. L. M. Baca, J. Turpin, D. C. Kalter, B. Hansen, J. M. Orenstein, C. W. Dieffenbach, R. M. Friedman, and M. S. Meltzer. 1990. Regulation of HIV replication in infected monocytes by IFN- $\alpha$. Mechanisms for viral restriction. $J$. Immunol. 145:2669-2676.

39. Poli, G., P. Bressler, A. Kinter, E. Duh, W. C. Timmer, A. Rabson, J. S. Justement, S. Stanley, and A. S. Fauci. 1990. Interleukin 6 induces human immunodeficiency virus expression in infected monocytic cells alone and in synergy with tumor necrosis factor $\alpha$ by transcriptional and post-transcriptional mechanisms. J. Exp. Med. 172:151-158.

40. Kornbluth, R. S., P. S. Oh, J. R. Munis, P. H. Cleveland, and D. D. Richman. 1989. Interferons and bacterial lipopolysaccharide protect macrophages from productive infection by human immunodeficiency virus in vitro. $J$. Exp. Med. 169:1137-1151.

41. Rosen, C. A., J. G. Sodroski, and W. A. Haseltine. 1985. The location of cis-acting sequences in the human T cell lymphotropic virus type III (HTLV III/LAV) long terminal repeat. Cell. 41:813-823.

42. Lu, Y., M. Stenzel, J. G. Sodroski, and W. A. Haseltine. 1989. Effects of long terminal repeat mutations on human immunodeficiency virus type 1 replication. J. Virol. 63:4115-4119.

43. Smith, M. R., and W. C. Greene. 1989 . The same 50-kDa cellular protein binds to the negative regulatory elements of the interleukin 2 receptor $\alpha$-chain gene and the human immunodeficiency virus type 1 long terminal repeat. Proc. Natl. Acad. Sci. USA. 86:8526-8530.

44. Diamond, M. I., J. M. Miner, S. K. Yoshinaga, and K. R. Yamamoto. 1990. Transcription factor interactions: selectors of positive and negative regulation from a single DNA element. Science (Wash. DC). 249:1266-1272. 